\title{
Licenciandos em Matemática e Situações da Matemática Escolar: um Estudo Exploratório sobre a Formação Inicial de Professores de Matemática
}

\author{
Undergraduates in Mathematics Teacher Education \\ and Situations of School Mathematics: \\ an exploratory study on the initial formation of \\ mathematics teachers
}

\author{
Claudia Laus Angelo \\ João Ricardo Viola dos Santos \\ Walderez Soares Melão
}

\begin{abstract}
Resumo
Neste artigo tivemos por objetivo investigar como licenciandos do último ano de um curso de licenciatura em matemática lidam com situações da matemática escolar. Por meio de uma abordagem qualitativa de pesquisa analisamos 36 produções escritas. Em meio à problemática de se configurar cursos de licenciatura em matemática que atendam as demandas da prática pedagógica de professores da educação básica, tecemos considerações sobre a formação inicial de professores de matemática. As discussões das situações e a produção escrita dos licenciandos podem servir de base para atividades formativas com futuros professores, que ultrapassem a categorização da formação Matemática e da Pedagógica.

Palavras-chave: Formação de professores; Licenciandos em matemática; Situações escolares.
\end{abstract}

\section{Abstract}

In this paper we had objective to investigate how senior students of a course mathematics teacher education deal with situations of school mathematics. Based on research qualitative approach we analyze 36 students written work. We point out some considerations about the problematic structure initial courses mathematics teacher education that it has focus in demands of pedagogic practice. The discussions of situations and the student written work can serve with base for activities to pre-service teachers. These activities go beyond Mathematical and Pedagogic categorization.

Key-words: Mathematics teacher education; pre-service teachers; school situations. 


\section{Introdução}

Os professores dos cursos de licenciatura em matemática que ministram as disciplinas de conteúdo matemático como Cálculo, Álgebra, Análise, geralmente se preocupam em oferecer aos licenciandos uma formação matemática sólida, com conceitos e demonstrações formalizados com rigor, construindo assim os ditos fundamentos da matemática. Os conceitos, procedimentos, algoritmos e técnicas são discutidos apenas em relação à matemática, pela e para a matemática. A resultante dessa discussão restrita ao conteúdo específico não propicia uma formação mais ampla, que abarque discussões sobre esses conteúdos com passagem pelas demandas e especificidades da prática pedagógica que os futuros professores vivenciarão na educação básica. Tendo como pressuposto que um curso de licenciatura tem seu viés principal na formação de professores, seria fundamental ressaltar aspectos relacionados à matemática escolar.

Num artigo que trata sobre as diversas aplicações da Matemática, Garbi (2007), reafirma a declaração que o professor Elon Lages Lima publicou na Revista do Professor de Matemática $n^{\circ}$ 28: “[...] o bom professor [de matemática] é aquele que vibra com a matéria que ensina, conhece muito bem o assunto e tem um desejo autêntico de transmitir esse conhecimento [...]" (GARBI, 2007, p. 5). Ele ainda acrescenta: "[...] são esses os professores que conseguem desenvolver em seus alunos o gosto pelo estudo da Matemática pelo que ela é em si mesma e não apenas por sua utilidade." (GARBI, 2007, p. 5). Concordamos que um bom professor deve conhecer e gostar da matéria que ensina, mas essa concepção é insuficiente frente à complexidade da sala de aula em seus aspectos culturais, sociopolíticos e científicos. Esta concepção sobre o que venha a ser um bom professor de matemática, sustentada por um discurso raso de tradição pedagógica, é a de boa parte dos professores formadores que lecionam conteúdos específicos nos cursos de licenciatura em matemática e se nota também na prática de alguns professores auto-intitulados educadores matemáticos que hesitam tanto em aceitar quanto em recusar completamente as noções que ela expressa.

Roberto Ribeiro Baldino (BALDINO, 2001, p. 85) produziu um texto denominado "A doutrina" no qual apresenta uma boa quantidade de idéias advindas dessa concepção. Ele afirma ter ouvido cada uma das frases citadas abaixo, durante vários anos de trabalho em Educação Matemática:

"Nossas universidades devem melhorar a formação matemática dos futuros professores e ter a coragem de terminar com disciplinas pedagógicas inúteis. (...) A matemática é a matemática e quem entende dela são os 
matemáticos, porque a matemática é aquilo que os matemáticos fazem. Todos os grandes matemáticos aprenderam com aulas expositivas de seus mestres (...). Deve-se tomar como lema da formação do professor: primeiro os conteúdos, depois os métodos (...). A preocupação prematura com problemas de ensino é perigosa, pois desvia o aluno do esforço que deve fazer para aprender matemática, no momento em que mais precisa disso. Portanto, na licenciatura, o essencial é garantir uma boa formação matemática nos primeiros semestres, concentrando-se as disciplinas pedagógicas no último ano, de preferência no último semestre."

Percebemos que formadores que se enquadram na doutrina têm um modelo de formação de professores que se sustenta no discurso de que para ensinar é preciso apenas saber bem o conteúdo. Por outro lado, acreditamos que sustentar um discurso que apenas valorize o conhecimento pedagógico em detrimento do conteúdo matemático também não contribui para melhorar a educação matemática. Um professor que conheça pouco sobre o conteúdo que pretende ensinar, não pode contar só com metodologias para suprir essa falta. Notamos que essa discussão ultrapassa a categorização de conteúdo matemático e conteúdo pedagógico. As demandas da educação básica são interdependentes e estão interligadas a esses dois eixos (matemático e pedagógico) que se misturam e configuram a formação inicial do professor de matemática. De acordo com Lins (2003, s.p.):

"O desafio para a comunidade da educação matemática é o de oferecer uma formação integrada e de acordo com as necessidades reais desses profissionais [professores e professoras de matemática]. E há, no Brasil e no exterior, uma grande comunidade trabalhando para criar licenciaturas a partir da idéia de integração: nas disciplinas "matemáticas", está presente a formação "pedagógica" e, nas disciplinas "pedagógicas", está presente a formação "matemática". É assim que acontece na escola - matemática e pedagogia não estão nunca separadas -, e é por isso que é assim que a formação de professores e professoras deve se dar; "pedagógico", aqui, deve ser entendido como bem mais do que "formas de transmitir bem o conteúdo" (...)."

Os cursos de licenciatura em matemática deveriam ter entre seus principais objetivos, a promoção de experiências diversificadas de ensino e aprendizagem incorporadas às discussões de conteúdos e oferecer um repertório consistente e coerente para a atuação do professor a partir das demandas escolares. Se o objetivo é formar professores, as disciplinas que compõem os currículos das licenciaturas em matemática 
devem ter suas características delineadas além da matemática ou da pedagogia, abrangendo possibilidades de conhecer e de lidar com a complexidade do trabalho educativo. De acordo com Moreira e David (2005, p. 52):

"A prática profissional do professor de matemática da escola básica é uma atividade complexa, cercada de contingências e que não se reduz a uma transmissão técnica e linear de um "conteúdo" previamente definido.

A nossa visão é a de que há uma distinção profunda e importante entre modos de conhecer os objetos matemáticos quando se visa a formação profissional para o trabalho de pesquisa na fronteira da teoria matemática ou quando, sob outra perspectiva, o objetivo é a formação profissional para o trabalho educativo no processo da escolarização básica."

Ponte (2002) relata que novos professores lamentam que nada do que aprenderam na formação inicial lhes serviu para alguma coisa e que só na prática profissional aprendem o que é importante. Na realidade brasileira essa problemática aparece nos mesmos termos e é fato também que esse estado de coisas vem se arrastando nas últimas décadas sem mudanças substanciais. Liberman (2003) assegura que tem ouvido muitas vezes nos cursos que ministra e nas conversas com professores o seguinte comentário: "Aprendemos pouco na nossa formação e nada do que aprendemos nos foi útil na sala de aula. Só, na nossa prática diária e nas conversas com outros professores e algumas vezes, nos cursos que fazemos, aprendemos o que é importante." (LIBERMAN, 2003, p. 7). Adiante, na mesma entrevista, ela afirma ainda que constata entre os professores "muitas vezes as mesmas dúvidas e os mesmos questionamentos que encontrava há 40 anos". (LIBERMAN, 2003, p. 7)

Não basta discutir se os cursos devem ter mais ou menos disciplinas matemáticas ou pedagógicas, mas investigar e tecer compreensões a respeito dos elementos que constituem as salas de aula da escola básica e a partir disso reformular os cursos de formação de professores de matemática.

Com base nestas reflexões iniciais fomos a campo investigar de que modo graduandos do último ano de um curso de licenciatura em matemática lidam com situações da matemática escolar, constituídas de dificuldades e questionamentos de alunos, que costumam aparecer na prática docente. Para tanto, apresentamos quatro situações a esses licenciandos e investigamos, por meio da produção escrita, como lidaram com tais situações. 


\section{Sobre a pesquisa}

Neste trabalho utilizamos metodologia de pesquisa qualitativa em função do objetivo da investigação e da natureza dos dados. Garnica (2004) sinaliza alguns aspectos deste tipo de pesquisa que reconhecemos como importantes neste caso, como a transitoriedade dos resultados, a não neutralidade do pesquisador e a impossibilidade de estabelecer regulamentações.

Os licenciandos1 que fizeram parte desta pesquisa representam parte dos formandos de um curso em período integral de licenciatura em matemática de uma Universidade Estadual do estado de São Paulo.

A produção dos dados consistiu na aplicação a estes alunos de um instrumento composto de quatro situações fictícias de sala de aula do Ensino Fundamental, a saber:

Situação 1 (Baseada no artigo de Angelo (2007))

Um aluno da $6^{\mathrm{a}}$ série pergunta para você por que menos vezes menos dá mais

$(-)$ x $(-)=(+)$. Como você lidaria com essa questão?

Situação 2 (Retirada do artigo de Angelo (2007))

Como você faria para explicar para uma criança de 11 anos a resolução da divisão $832 \div 4 ?$

\section{Situação $3^{2}$}

\footnotetext{
${ }^{1}$ Vamos nos referir aos participantes da pesquisa sempre no gênero masculino, embora três participantes da pesquisa sejam do sexo masculino e seis do sexo feminino.

2 Adaptada da questão discursiva $n^{\circ} 40$ do ENADE 2005 - Matemática, específica para estudantes de licenciatura. Disponível em http://www.inep.gov.br / download / enade / 2005/ provas/ MATEMATICA.pdf
} 
Em uma avaliação de matemática de 5. ${ }^{\text {a }}$ série, a situação proposta exigia que fosse calculado o quociente entre 8 e 7 . O professor observou que uma aluna registrou o seguinte.
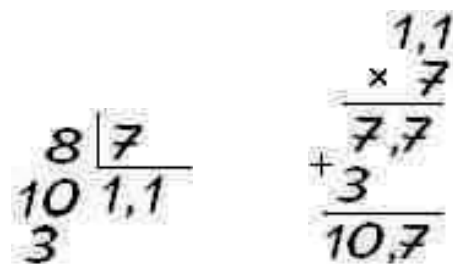

Que tipo de intervenção pode realizar o professor para que essa aluna supere tal dificuldade?

\section{Situação $4^{1}$}

Um professor resolve a seguinte equação no quadro com seus alunos de $6^{\mathrm{a}}$ série.

$$
10-3 \mathrm{x}=100
$$

Professor: Como a gente faz?

Aluno: A gente tem que passar o 10 para o outro lado com o sinal trocado.

$$
-3 \mathrm{x}=100-10
$$

Professor: E agora?

Aluno: Agora a gente tira 10 de 100, resultando 90 .

$$
-3 x=90
$$

Professor: E agora?

Aluno: Passa o - 3 para o outro lado dividindo com o sinal trocado.

$$
\mathrm{x}=90 / 3
$$

Se você estivesse no lugar desse professor, como lidaria com essa situação?

Fizeram parte da nossa amostra nove alunos, indicados aqui pelas letras de $A$ até I, que responderam as questões em horário de aula cedido por um professor para a realização da pesquisa.

As situações foram escolhidas tendo em vista possíveis dificuldades dos alunos da educação básica. Não tivemos a intenção de selecioná-las por blocos de conteúdos, simplesmente escolhemos situações que nos pareceram interessantes dentre tantas questões que freqüentemente surgem como dúvidas de licenciandos ou que geralmente são fonte de angústia para os alunos da escola básica. A Situação 1 apresenta uma dúvida sobre a regra de sinais na multiplicação de números inteiros que, inclusive, foi tema de um debate extenso na lista de discussão da SBEM (Sociedade Brasileira de Educação Matemática), no ano de 2006. As situações

${ }^{1}$ Elaborada pelos autores e inspirada no livro "Perspectivas em aritmética e álgebra para o século XXI" de Lins e Gimenez (1997). 
2 e 3 estão relacionadas ao algoritmo da divisão e a compreensão do sistema decimal de numeração. Segundo Moreira e David (2005, p. 58):

"O uso dos algoritmos formais para as operações básicas (...) traz á tona a questão da lógica do seu funcionamento e coloca, para o professor da escola básica, a necessidade de uma percepção clara dos princípios em que se baseia a sua justificativa, ou seja, a razão pela qual eles fornecem corretamente os resultados".

A divisão, em termos da execução do seu algoritmo, é uma operação, em geral, considerada difícil em comparação com as demais operações básicas. Na Situação 2, aparece um zero no quociente da divisão e ficamos curiosos em observar como os licenciandos explicariam a presença desse zero. Na Situação 3, a questão se refere ao resto de uma divisão no campo dos números racionais e a sua utilização na "prova real".

A Situação 4 diz respeito à resolução de uma equação do primeiro grau na qual o aluno fictício comete alguns erros ao utilizar a idéia que chamaremos aqui de "passa-passa"1.

A seguir realizaremos uma análise horizontal das produções dos alunos, ou seja, vamos olhar para todas as respostas dadas à Situação 1 e agrupá-las de acordo com características observadas nessas produções. Procederemos do mesmo modo para as situações 2, 3 e 4 tecendo considerações gerais para cada situação.

\section{Situação 1}

Na Situação 1 alocamos as produções dos licenciandos em quatro grupos.

O grupo 1 contém apenas uma produção. Nesta, o licenciando E escreveu "não sei" como resposta para a situação. Podemos pensar que ele não sabe como lidar com essa questão numa situação de ensino, ou que não sabe por que "menos com menos dá mais", ou mesmo que preferiu não pensar a respeito, entre outras coisas.

No grupo 2, quatro licenciandos ( $\mathrm{B}, \mathrm{C}, \mathrm{F}$ e I) utilizaram um argumento matemático para lidar com a questão. Nessas produções aparecem justificativas vinculadas a

\footnotetext{
${ }^{1} \mathrm{Na}$ resolução de uma equação é comum alunos e também professores falarem em "passar" os termos de um lado da equação para o outro lado da equação invertendo a operação. Por exemplo, se o termo está somando "passa" subtraindo, se está multiplicando, "passa" dividindo".
} 
explicações de cunho matemático. O aluno $\mathrm{F}$ comentou que durante o curso, nunca foi "atrás para saber" o que nos faz pensar que o assunto ou não foi tratado, ou não fez sentido para o aluno quando foi tratado. O mesmo aluno disse que somente se preocupou com esta questão quando foi fazer estágio e percebeu que os alunos da escola tinham dificuldade com as regras de sinais. Então ele questionou uma professora sobre o assunto e obteve a seguinte explicação: "era devido às propriedades dos conjuntos numéricos, como por exemplo, os inteiros, que para ser válida a distributiva, menos vezes menos teria que dar mais. Ela usou um exemplo para me mostrar o que aconteceria se (-) $x(-)=(-)$, e acho que isto esclareceu de um modo muito claro minha dúvida". Como o questionamento aconteceu durante o estágio, há possibilidade de ter sido feito para a própria professora responsável pelo estágio.

O licenciando B produziu a seguinte resposta:

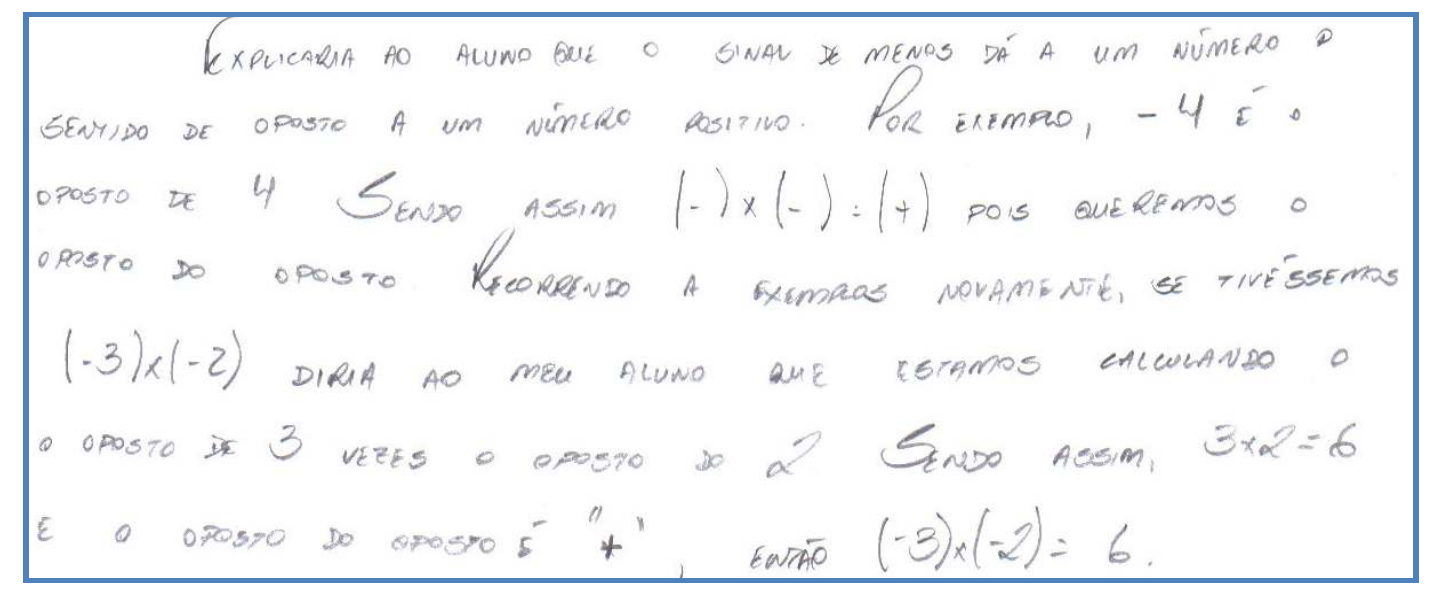

Figura 1 - Produção escrita do licenciando B

Nas produções escritas dos licenciandos ( $\mathrm{C}$ e I) há uma justificativa geométrica como possibilidade de argumentação para um aluno de 6a série. Isto nos fez pensar que, provavelmente, tal justificativa tenha sido discutida durante alguma disciplina, pois um deles (I) escreveu "(...) eu não aprendi isso na escola, somente na universidade, e quando vi achei muito interessante, principalmente por se tratar de algo geométrico." Ambos consideraram esta justificativa geométrica passível de ser compreendida por um aluno de 6a série. A seguir temos a produção do aluno C: 


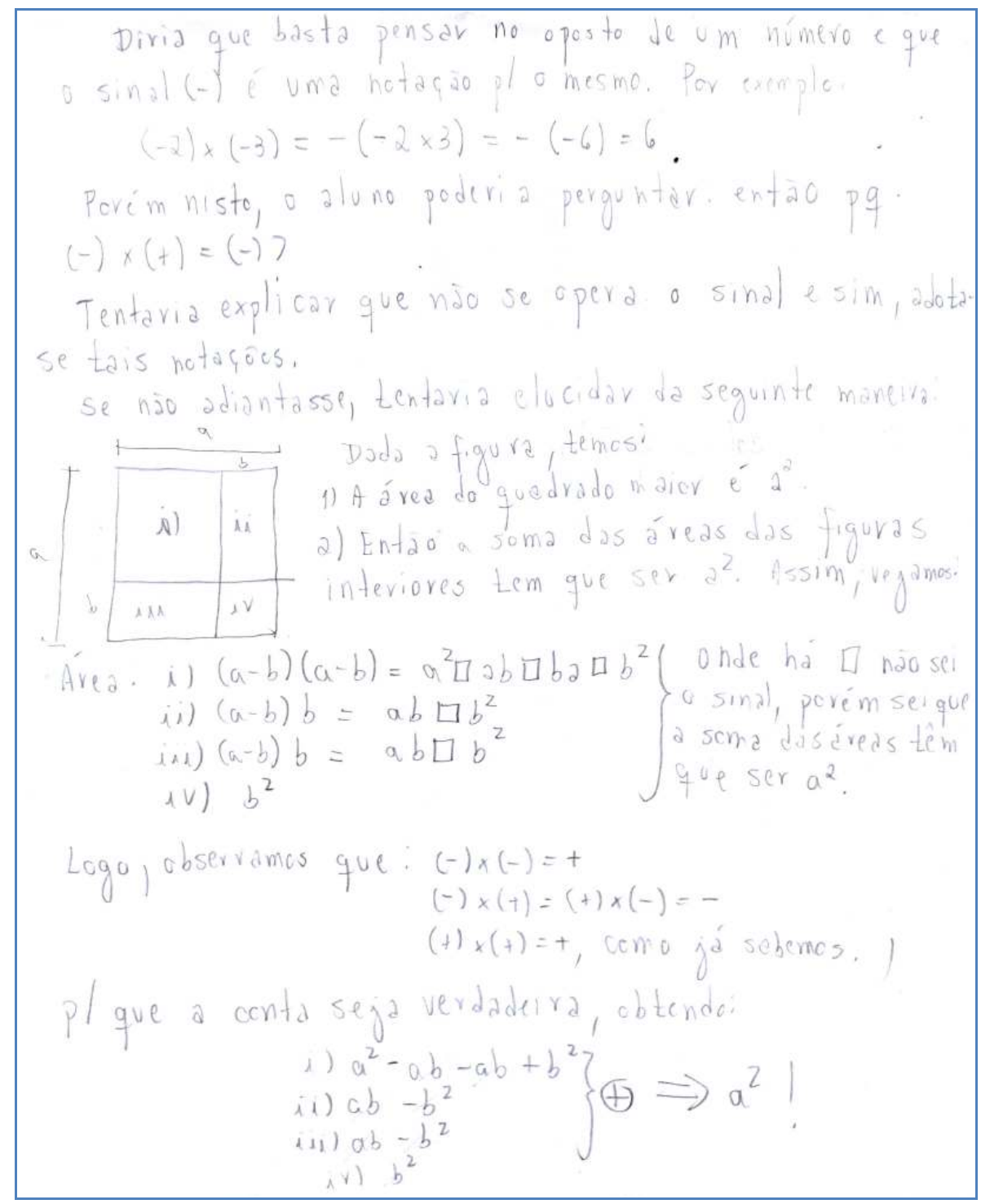

Figura 2 - Produção escrita do licenciando C

$\mathrm{O}$ graduando $\mathrm{C}$ apresentou primeiro um argumento baseado no oposto e, para o caso deste não funcionar, apresentou o argumento geométrico descrito acima. No entanto, a justificativa geométrica pensada para um aluno de 6a série, contém manipulações algébricas e operações com polinômios que geralmente são trabalhadas apenas na 7ạ série.

O grupo 3 contém as produções de dois alunos ( $A$ e $G$ ) que responderam a questão mencionando que é por definição que menos vezes menos é igual a mais. $\mathrm{Na}$ graduação, muitas vezes vários resultados são justificados com essa afirmação, sendo que para grande parte dos licenciandos é uma afirmação natural. Entretanto, para os alunos 
do Ensino Fundamental, possivelmente afirmações dessa natureza não soam tão naturais como para os licenciandos e provavelmente se essa resposta fosse dada a um aluno de 6a série, ele a aceitaria apenas pelo fato de que é o professor que diz e, então, com certeza é uma resposta válida. Consideramos importante discutir com os alunos a maneira pela qual se estrutura a matemática escolar e explicitar que em alguns casos são utilizados argumentos definicionais. Ressaltamos que na produção escrita desses licenciandos temos apenas uma resposta pontual e estática, sem discussões sobre a validade e aceitabilidade desse tipo de resposta.

No grupo 4 temos outros dois alunos ( $\mathrm{D}$ e $\mathrm{H}$ ) que responderam que é por convenção que $(-) \times(-)=(+)$. Entretanto, mencionaram que essas convenções foram assumidas para que "as contas façam sentido"; "tudo dê certo no final". Notamos que nas respostas desses licenciandos já aparece uma discussão sobre o porquê dessas convenções. Essa discussão, embora resumida, já oferece elementos para os alunos da escola entenderem como se estrutura a matemática escolar.

O licenciando D ainda escreve: "Gostaria de estudar um pouco mais sobre isso e como apresentar esse conteúdo $p /$ um aluno de 6모 serie." Tal comentário nos faz pensar que se o formando sente necessidade de estudar um pouco mais sobre isso, talvez o curso não tenha proporcionado oportunidades diferenciadas de discussão sobre esta questão, ou as discussões que aconteceram não fizeram sentido para este aluno, no momento que foram oferecidas. Em se tratando de uma situação que sempre aparece no cotidiano escolar, pensamos que a afirmação do licenciando $D$ remete a uma discussão tanto sobre as experiências vividas por esses licenciandos durante a graduação quanto sobre os conteúdos que são oferecidos pelo curso.

Em relação a esses quatro grupos notamos que as justificativas apresentadas pelos licenciandos são caracterizadas por: desconhecimento de uma justificativa, "não sei como explicaria"; argumentos matemáticos (propriedades dos conjuntos numéricos, ou da geometria); definições matemáticas, "na matemática existe regras (...) e uma dessas é a dos sinais"; e, convenções, "para que as contas façam sentido". Nos grupos 2 a 4 percebemos que os licenciandos utilizam exemplos, tanto aritméticos quanto geométricos, para lidar com a situação. Essa é uma característica presente em grande parte das produções escritas dos licenciandos em relação a essa situação. 


\section{Situação 2}

Com as produções referentes à Situação 2 formamos três grupos.

O grupo 1 contém três produções $(A, D, F)$ nas quais os graduandos mencionaram a utilização do material dourado para a explicação dessa divisão. Nas respostas também apareceu uma vinculação da utilização do material dourado com o algoritmo euclidiano da divisão $^{1}$ (dividendo $=$ divisor $\mathrm{x}$ quociente + resto). Notamos que esses alunos conhecem estratégias e materiais manipulativos que oferecem possibilidades para a aprendizagem dos alunos que vão além do algoritmo tradicional. Nessas produções há preocupações dos licenciandos em relação a como se estrutura o sistema de numeração decimal, em termos de unidades, dezenas e centenas e não apenas a essa divisão.

O grupo 2 contém uma única produção na qual o aluno $\mathrm{C}$ explica passo a passo o algoritmo euclidiano escolar da divisão. No entanto, com relação ao número zero que aparece no quociente, faz a seguinte observação:
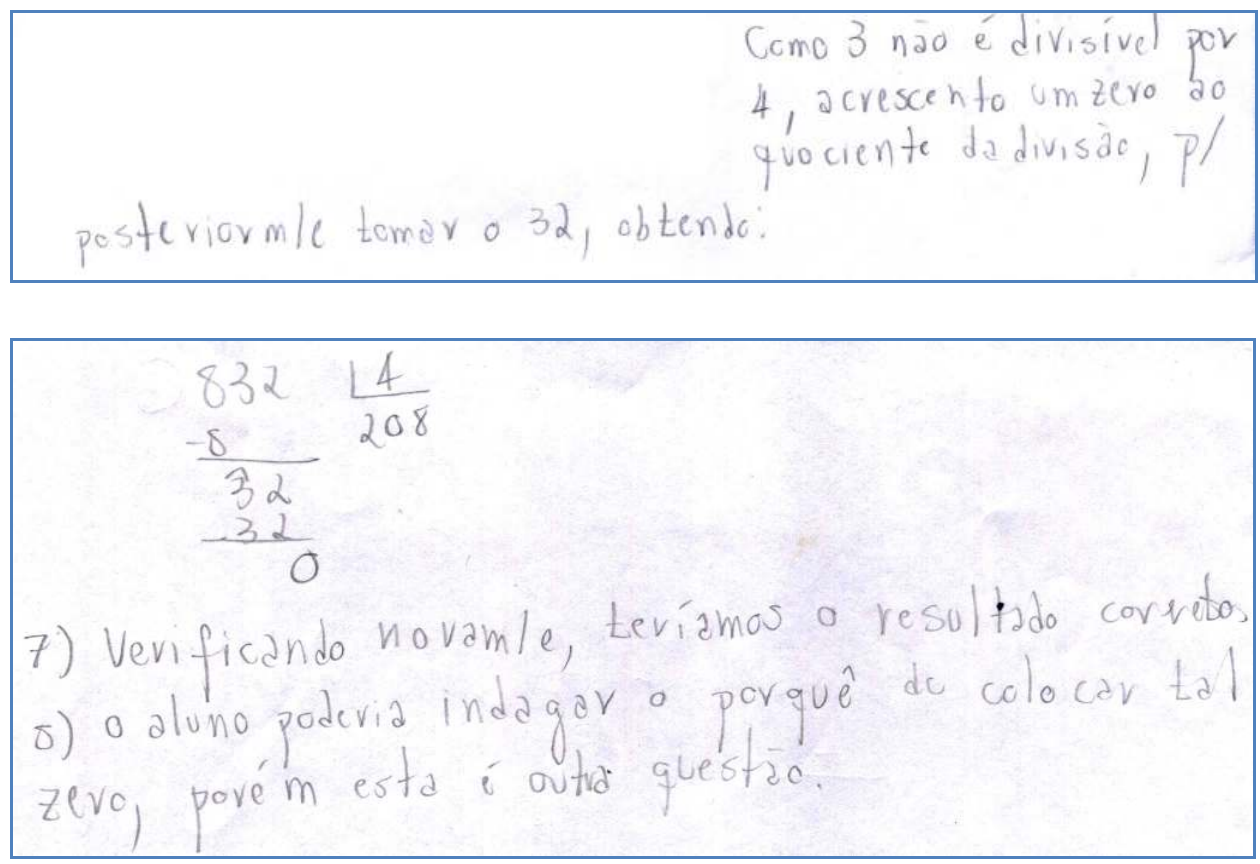

Figura 3 - Parte da produção escrita do licenciando $C$

Nessa produção notamos uma peculiaridade muito interessante, pois justamente aquilo que estávamos interessados em conhecer sobre seu modo de lidar com uma

\footnotetext{
${ }^{1}$ Geralmente na escola o algoritmo euclidiano é apresentado da seguinte forma: $\frac{D}{\pi} \frac{L d}{8}$
} 
situação da matemática escolar - como explicar a presença do zero no quociente da divisão - foi considerado como uma questão para ser tratada em outro momento. Nas palavras do aluno: "esta é uma outra questão". Muitas vezes os alunos entram no curso de licenciatura e passam quatro anos discutindo tópicos de matemática superior e pouca atenção é dispensada a temas que são de extrema importância para o processo de produção de significados dos alunos na construção dos algoritmos. Como conseqüência, passam a apresentar justificativas vagas que não contribuem para a construção de uma lógica válida da matemática escolar. Nas palavras do licenciando expressas na figura 3, observamos a limitação do seu argumento. Para alunos do Ensino Fundamental esse tipo de explicação pode ser posto na categoria dos "passes de mágica", isto é, procedimentos que o professor executa e os alunos reproduzem sem uma explicação consistente a respeito.

No grupo 3 temos cinco produções nas quais os graduandos responderam a questão partindo da idéia de decomposição do dividendo. Em quatro delas escreveram que explicariam para os alunos essa divisão sem utilizar o algoritmo euclidiano escolar. Apenas uma produção trata do algoritmo, porém o licenciando apontou a utilização de um algoritmo no qual, além das subtrações sucessivas no dividendo, aparece uma adição para a obtenção do quociente.

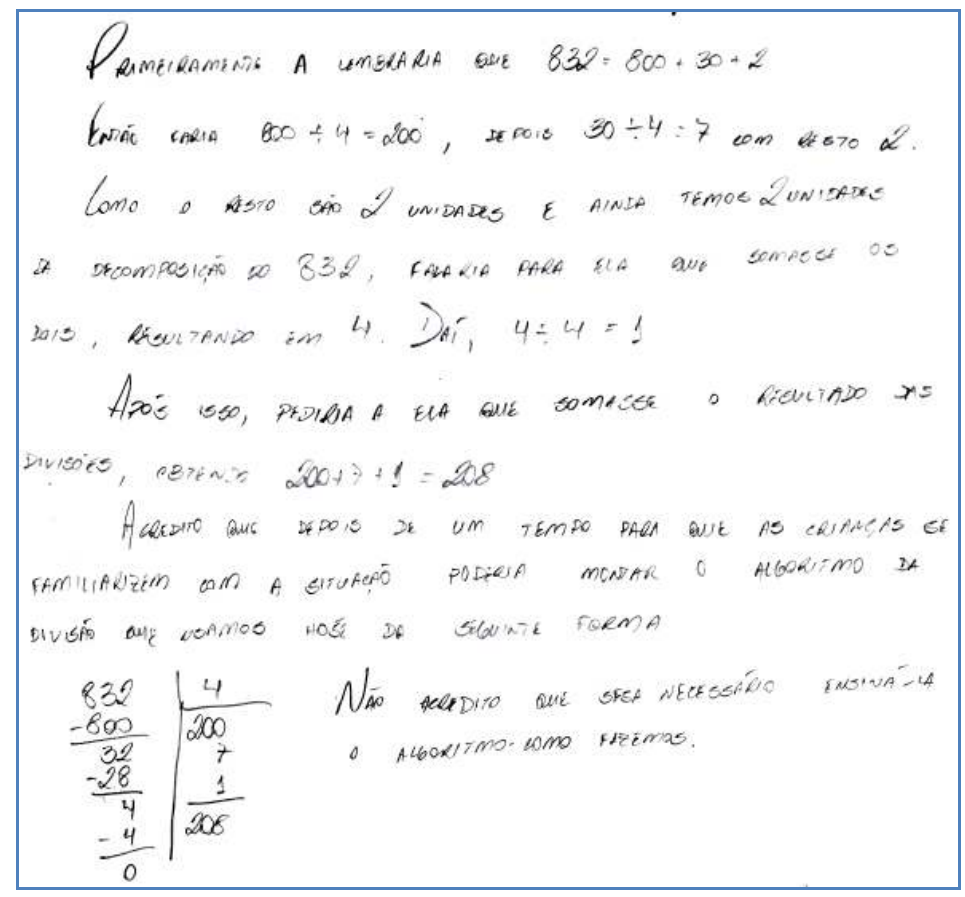

Figura 4 - Produção escrita do licenciando $B$ 
Notamos que os licenciandos desse grupo apresentaram conhecimentos da prática escolar em relação à preferência de um procedimento de resolução em detrimento de outro. Além de mostrarem outra maneira para se tratar a divisão de números naturais, eles afirmaram não ser necessário ensinar aos alunos da educação básica o algoritmo euclidiano escolar. Considerando as produções é possível dizer que eles têm estratégias didáticas para lidar com esse tipo de situação e que essas foram elaboradas, possivelmente, tendo como ponto de partida o contexto da sala de aula.

Na maior parte das produções relativas à Situação 2 percebemos que os licenciandos mostraram conhecimentos sobre a utilização do material dourado e justificaram a utilização de estratégias didáticas, como a decomposição dos números.

\section{Situação 3}

Alocamos as produções dos alunos referentes à Situação 3 em quatro grupos.

No grupo 1 temos duas produções $(B, D)$ nas quais os licenciandos identificaram a dificuldade da aluna e depois informaram a ela a maneira considerada correta. $\mathrm{O}$ aluno $\mathrm{B}$ elaborou a seguinte resposta:

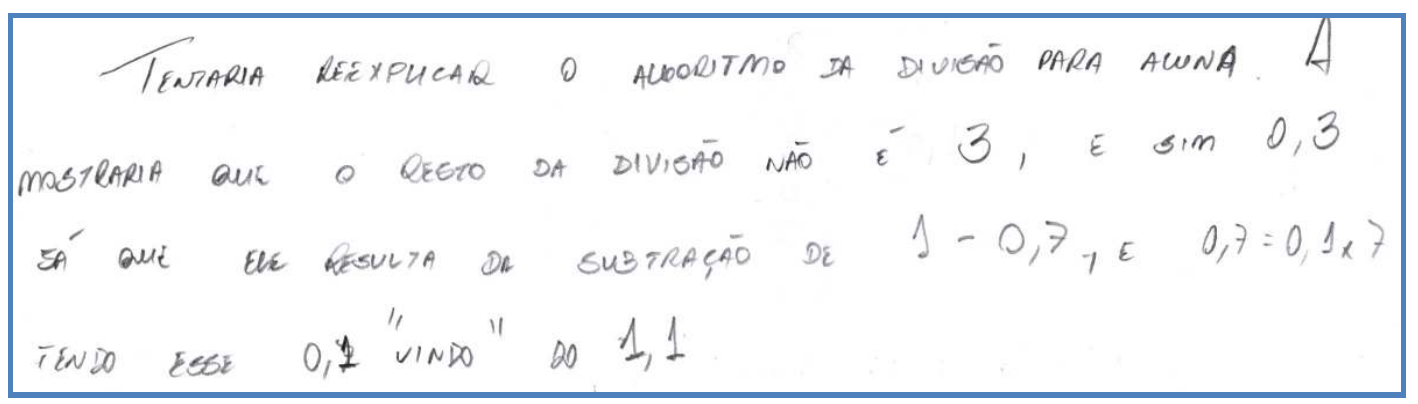

Figura 5 - Produção escrita do licenciando B

Nessas produções vemos que os licenciandos notaram a dificuldade da aluna e utilizaram uma estratégia do modelo tradicional de ensino, que se caracteriza pela mera apresentação do correto sem a tentativa de entender onde possa estar a dificuldade que a levou ao erro. Nas duas produções $(E, H)$ do grupo 2, os graduandos explicaram todo o algoritmo da divisão e o processo de transformação de um inteiro em dez décimos. $O$ licenciando $\mathrm{E}$, inclusive, mencionou que, se possível, mostraria esta transformação com o material dourado. Na produção $\mathrm{H}$ o licenciando construiu um diálogo com possíveis perguntas que faria à aluna e respostas que ela the daria. Notamos que esse licenciando mostrou uma estratégia de interagir e intervir no processo de produção de significados da 
aluna, não apenas mostrando o correto em detrimento do errado, mas colocando a aluna a pensar e negociando regras que podem, ou não, ser válidas para esse contexto.

Nas duas produções (A e I) do grupo 3, os graduandos atentaram apenas para a divisão (8 por 7 ) indicando que esta deveria continuar, sem fazer qualquer referência à dificuldade da aluna em relação à utilização do resto da divisão na prova real.

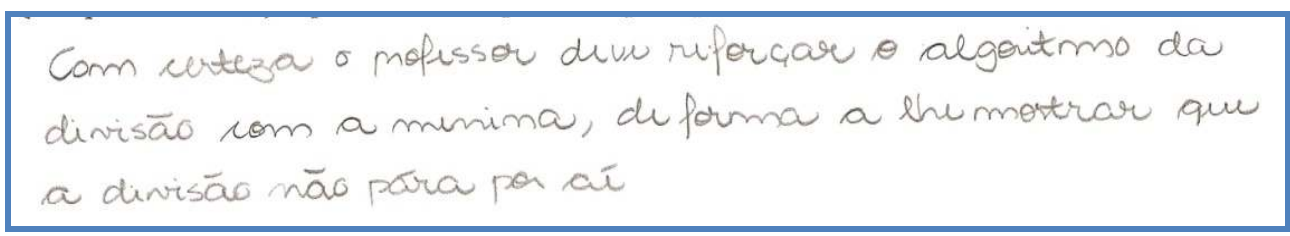

Figura 6 - Produção escrita do licenciando I

Nessas produções escritas não há informações que nos possibilitem tecer considerações sobre que tipo de intervenção eles fariam. Entretanto, parece-nos lícito apontar que a afirmação feita pelo Licenciando I "o professor deve reforçar o algoritmo da divisão com a menina" tem suas raízes em um tipo de concepção de ensino que não busca saber quais as dificuldades que os alunos apresentam, mas que reforça a prescrição de procedimentos.

No grupo 4 temos duas produções ( $F$ e $G$ ) nas quais os graduandos indicaram não saber como fazer para a aluna superar a dificuldade. Percebemos que esses licenciandos não conseguiram elaborar uma estratégia que contemplasse as dúvidas dessa aluna. Esse conhecimento está ligado ao contexto da matemática escolar e para ser constituído, precisa tomar como ponto de partida a sala de aula.

No grupo 5 temos uma única produção (C) na qual o graduando ofereceu a seguinte explicação: "Basta dizer que a operação inversa só pode ser feita no primeiro passo da divisão ou qdo. a divisão for exata, obtendo:

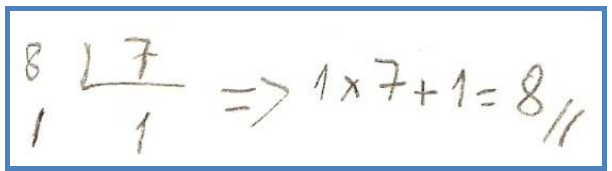

Figura 7-Parte da produção escrita do licenciando $C$ 
Esse licenciando apenas tratou de prescrever um caminho a ser seguido sem tecer considerações sobre qualquer intervenção poderia levar a aluna a refletir sobre sua produção e a superar a dificuldade apresentada.

Em relação à Situação 3, uma parte dos licenciandos mostrou estratégias que usaria para que a aluna superasse sua dificuldade, tanto apresentando uma maneira correta, quanto negociando um processo de produção de significados para a situação. Entretanto, nas produções de outros licenciandos percebemos desconhecimento de qualquer modo de lidar com a situação.

\section{Situação 4}

As produções dos licenciandos na Situação 4 foram separadas em quatro grupos.

O grupo 1 contém duas produções (C, I) nas quais os graduandos responderam que lidariam com essa situação usando a metáfora que compara a equação a uma balança de dois pratos. Assim, exemplificariam os princípios aditivo e multiplicativo da igualdade e todo o processo de resolver a equação. O aluno I escreveu "(...) compararia uma equação do 1o grau à uma balança. (...) Mas para isso, é necessário subtrair 10 desse membro. No entanto, como se trata de uma balança, é necessário também subtrair 10 do segundo membro, e assim por diante.

Em relação às respostas desses licenciandos, notamos que eles se apropriaram de uma estratégia didática para lidar com esse conteúdo e sabem como implementá-la. É fato que essas discussões sobre os processos de ensino e aprendizagem de equações e a metáfora da balança de dois pratos são sempre ressaltadas em livros, palestras e congressos. Percebemos que os licenciandos $\mathrm{C}$ e I conseguiram, em uma situação escolar fictícia, lidar com as dificuldades dos alunos utilizando essa estratégia.

No grupo 2 estão as produções D e E nas quais os licenciandos explicaram o que significa o "passa-passa", como sendo ações de somar, subtrair, multiplicar ou dividir igualmente em ambos os lados da equação. O licenciando D escreveu que "tentaria explicar o que realmente acontece, fazendo a mesma operação dos dois lados, para que o aluno realmente soubesse o que estava fazendo."

O grupo 3 contém as produções $A, H$ e $F$, nas quais os licenciandos também explicaram o que significa o "passa-passa" para os alunos, porém articularam o processo de adicionar e multiplicar em ambos os lados com a maneira que os alunos geralmente fazem (passa pra lá, passa pra cá). Assim, caso os alunos compreendessem esses 
processos e tivessem sucesso nas resoluções utilizando-o, legitimariam esse procedimento de resolução das equações. A produção do licenciando H ilustra bem isso.

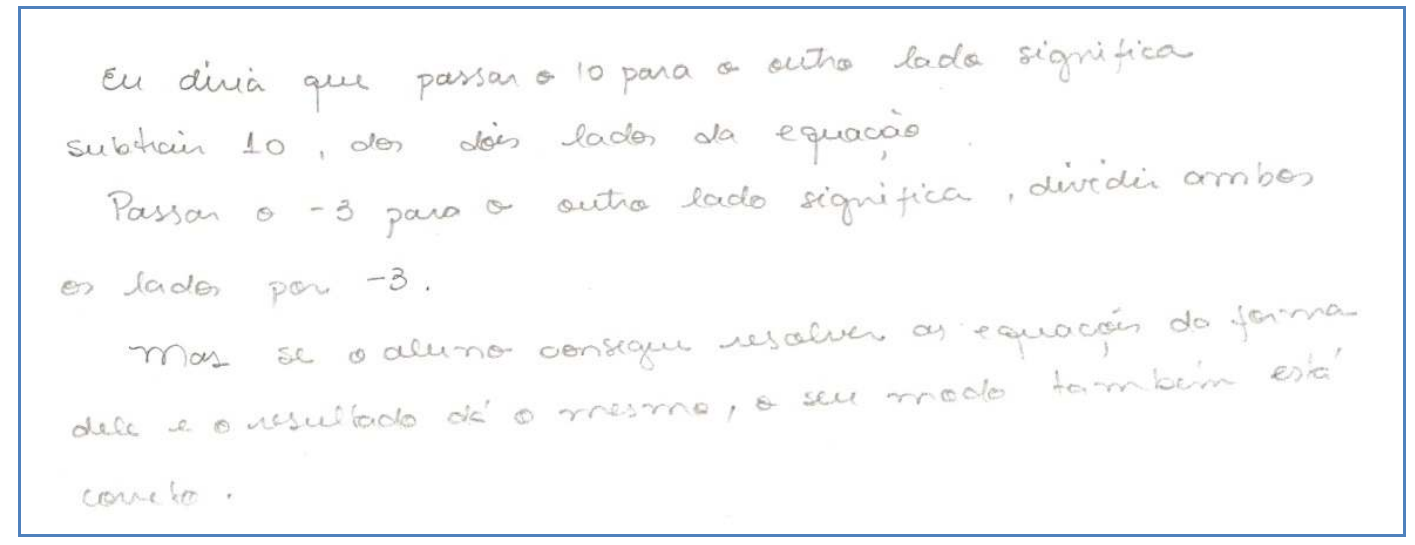

Figura 8 - Produção escrita do licenciando $H$

No grupo 4 estão as produções B e $G$ nas quais os graduandos afirmaram que como os alunos já aprenderam essa forma de resolver equações, eles apenas lembrariam as trocas de sinais. Eles argumentaram que se fossem explicar a idéia de oposto e inverso, possivelmente confundiriam mais os alunos. Essa opção é muitas vezes a de professores em suas classes: se os alunos estão acertando, não há necessidade de apresentar alternativas, de levantar discussões sobre os assuntos. Esse é um modo bastante conservador de lidar com o conhecimento matemático escolar. Na produção a seguir, do licenciando $B$, vemos o que ele escreveu referente a essas considerações:

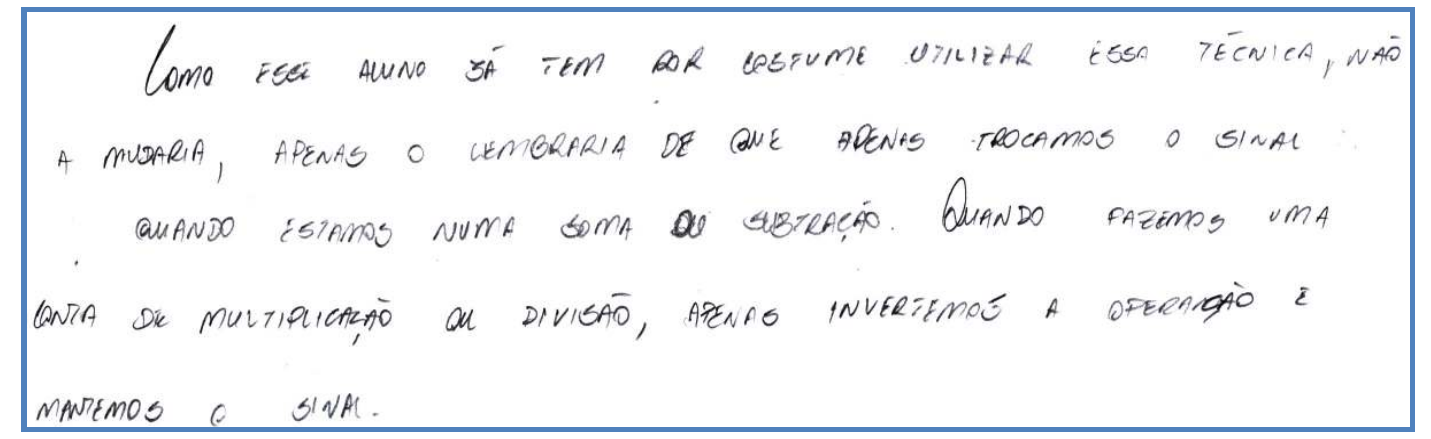

Figura 9 - Produção escrita do licenciando B

$\mathrm{Na}$ maior parte das produções referentes a essa situação percebemos que os licenciandos tiveram clareza dos métodos e procedimentos que utilizaram para explicar e justificar suas respostas, o que mostra certo grau de reflexão sobre as estratégias didáticas que envolvem resolução de equações. 


\section{Considerações Finais}

É possível constatar, por meio da produção escrita dos licenciandos que, de maneira geral, eles têm um repertório de conhecimentos que lhes permite lidar com as situações escolares apresentadas. Em suas produções reconhecemos estratégias que utilizam materiais didáticos e sua implementação, outras que eles justificam ser mais eficazes para a aprendizagem dos alunos em detrimento daquelas mais convencionais. Também notamos maneiras de interagir com o processo de produção de significados dos alunos, tal como um possível diálogo entre um professor e um aluno. Ficamos agradavelmente surpresos com essa análise, pois nossa expectativa a priori era que eles apresentariam mais dificuldades em lidar com as situações propostas, e que muitas das suas respostas estariam pautadas em afirmações soltas e pouco articuladas com o contexto da matemática escolar.

Entretanto, não podemos deixar de destacar algumas fragilidades nas respostas dos licenciandos, tanto ligadas às justificativas utilizadas, que em alguns casos apenas reafirmam o discurso matemático sem uma discussão de como ele se estrutura e o porquê de sua validade, quanto no desconhecimento de estratégias para lidar com algumas situações. Outro aspecto que não podemos perder de vista são as particularidades dos licenciandos que participaram desse estudo e da instituição pela qual estão sendo formados. Eles cursam uma licenciatura em matemática que é oferecida em período integral e que faz parte de um instituto que também abriga um dos mais conceituados programas de pós-graduação em Educação Matemática.

Dentre essas considerações e as limitações desse estudo exploratório apontamos elementos, tais como a superação das categorias pedagógica e matemática na formação inicial do professor de matemática, os alinhavos sobre as maneiras como os licenciandos deste estudo lidaram com situações da matemática escolar, que evidenciam a necessidade de mais pesquisas sobre o processo de construção de conhecimentos dos futuros professores em um curso de formação inicial que apontem quais experiências possibilitariam modos de se pensar e configurar, nesses cursos, as dimensões da matemática escolar. Nessa perspectiva, a discussão dessas situações bem como da produção escrita desses licenciandos podem servir de base para uma atividade formativa de futuros professores de matemática. Uma atividade Matemática, pois estaria discutindo certos modos de se pensar a matemática escolar, e ao mesmo tempo Pedagógica, na medida em que interroga as maneiras de se elaborar e implementar estratégias para o processo de produção de significados dos alunos. 
Há algumas questões ainda a serem pesquisadas e respondidas, tais como: Em que momento do curso foram oferecidas oportunidades para os alunos discutirem questões que lhes permitiram lidar com as situações? Qual a influência das disciplinas consideradas de conteúdo matemático na resolução das situações, visto que em algumas delas, se pedia uma justificativa para um resultado matemático? Quais experiências foram significativas para os licenciandos cujas respostas apresentaram um diálogo entre professor e aluno, indo além da simples prescrição de procedimentos? Essas, entre outras, são questões que deixamos em aberto e que apontam outras investigações a serem realizadas.

A formação exige prática (Lins, 2003) e um olhar focado no contexto escolar. Essa afirmação remete a uma discussão sobre os licenciandos e as situações da matemática escolar. Não menos que interessante e mais que necessária para configurar cursos de licenciatura em educação matemática.

\section{Referências}

ANGELO, C. L. Concepções de futuros professores sobre a multiplicação de números inteiros. In: IX ENCONTRO NACIONAL DE EDUCAÇÃO MATEMÁTICA, 2007, Belo Horizonte. Anais...Belo

Horizonte, 2007. 1 CD.

BALDINO, Roberto R. Grupos de Pesquisa-Ação em Educação Matemática. Bolema, Rio Claro, v. 14, ano 14, p. 83-98, 2001.

GARBI, G. G. Para que serve isso? Revista do Professor de Matemática, São Paulo, 2. quad. 2007, n. 63, p. 01-05, 2007.

GARNICA; A. V. M. História Oral e Educação Matemática. In: Pesquisa Qualitativa em Educação

Matemática. BORBA, M. C.; ARAUJO, J. L. (orgs.) Belo Horizonte: Autêntica, 2004.

LIBERMAN, M. P. Entrevista. Educação matemática em revista. Ano 10. n. 15, p. 05-07, dez. 2003.

LINS, R. C. A formação exige prática. Nova Escola, São Paulo, p. 14, 01 set. 2003.

Polêmica: os problemas da educação matemática. Folha Online, São Paulo, 29 abr. 2003. Disponível em: http://www1.folha.uol.com.br/folha/sinapse/ult1063u385.shtml. Acesso em: 20 out. 2008.

Characterizing the mathematics of the mathematics teacher from point of view of meaning production. In: ICME 10, p.1-13. 2004a, Copenhagen-Denmark. Proceedings... Copenhagen. 
Matemática, monstros, significados e educação matemática. In: BICUDO, M. A. V. \& BORBA, M. C. (Orgs.). Educação Matemática: pesquisa em movimento. São Paulo: Cortez, 2004b. p. $92-120$.

LINS, R. C.; GIMENEZ, J. Perspectivas em aritmética e álgebra para o século XXI. Campinas, SP: Papirus, 1997. (Perspectivas em Educação Matemática)

MOREIRA, P. C.; DAVID, M. M. M. S. Matemática escolar, matemática científica, saber docente e formação de professores. Zetetiké, v.11, n.19, pp. 57-80, 2003.

A formação matemática do professor: licenciatura e prática

docente. Belo Horizonte: Autêntica, 2005. 120p. (Tendências em Educação Matemática, 11). O conhecimento matemático do professor: formação e prática docente na escola básica. Revista Brasileira de Educação. Jan-abr. n. 28. São Paulo. p.5061, 2005.

PONTE, J. P. A vertente profissional da formação inicial de professores de matemática. Educação Matemática em Revista. Ano. 9. Edição Especial, p. 17-22, 2002.

SZTAJN, P. O que precisa saber um professor de matemática? Uma revisão de literatura americana dos anos 90. Educação Matemática em Revista. Ano. 9. Edição Especial, p. 17-22, 2002.

Claudia Laus Angelo é professora do Curso de Matemática da Universidade Federal do PampaUnipampa, campus de Bagé-RS. Doutoranda em Educação Matemática na Universidade Estadual Paulista, UNESP, campus de Rio Claro-SP. claudia.angelo@unipampa.edu.br João Ricardo Viola dos Santos é professor do Curso de Matemática Modalidade a Distancia da Universidade Federal do Mato Grosso do Sul. Doutorando em Educação Matemática na Universidade Estadual Paulista, UNESP, campus de Rio Claro-SP. Jr.violasantos@gmail.com Walderez Soares Melão é doutoranda em Educação Matemática na Universidade Estadual Paulista, UNESP, campus de Rio Claro-SP.walmelao@hotmail.com 